\title{
HYDROTREATMENT KATALITIK MINYAK RINGAN DENGAN KATALIS NiMo DAN PENGARUH SPESIES NITROGEN
}

\author{
Sri Djangkung Sumbogo Murti ${ }^{1)}$, Hartiniati ${ }^{2)}$ dan Agustina Eliyanti ${ }^{3)}$ \\ 1) Balai Besar Teknologi Energi, B2TE, Puspiptek, Serpong \\ 2) Pusat Teknologi Pengembangan Sumberdaya Energi, BPPT \\ BPPT Gedung II Lantai 22, Jalan MH Thamrin No 8, Jakarta 10340 \\ ${ }^{3)}$ Pusdal Mutu Pertamina Pulo Gadung Km 20 \\ e-mail: sumbogomurti@yahoo.com
}

\begin{abstract}
Gas Oil fraction of petroleum was hydrotreated (hydrodesulfurization, HDS) over $\mathrm{NiMo} / \mathrm{Al}_{2} \mathrm{O}_{3}$ catalyst in a $100 \mathrm{ml}$ autoclave reactor. The reaction was conducted at $340{ }^{\circ} \mathrm{C}$ under $5 \mathrm{MPa} \mathrm{H}_{2}$ pressure for $60 \mathrm{~min}$. to investigate the correlation of nitrogen species in the HDS. The inhibition effects of these species are also investigated by using original and its $N$-free gas oil. Hydrogen renewal between stages was attempted to reveal an additional effect of the by-products such as $\mathrm{H}_{2} \mathrm{~S}$. All species in the gas oils were analyzed by GC-AED before and after hydrotreatment. HDS over $\mathrm{NiMo} / \mathrm{Al}_{2} \mathrm{O}_{3}$ was largely improved by removal of nitrogen species. Refractory sulfur species were effectively removed by the removal of nitrogen species and renewal of hydrogen in staged HDS, showing synergy effects due to simultaneous removal of two inhibitors.
\end{abstract}

Kata kunci: gas oil, hydrodesulfurization, nitrogen inhibition, GC-AED

\section{PENDAHULUAN}

Kebutuhan bahan bakar minyak untuk transportasi dari tahun ke tahun terus meningkat. Pencairan batubara diharapkan dapat memasok bahan bakar tersebut untuk menurunkan ketergantungan pada produk minyak bumi karena pasokan minyak mentah mungkin tidak bisa memenuhi meningkatnya permintaan dalam waktu dekat. Tetapi, minyak batubara (CLO, Coal Liquid Oi) cenderung memiliki lebih banyak heteroatom seperti sulfur, nitrogen dan oksigen dalam fraksi minyak ringan dibanding produk dari minyak bumi. Beberapa heteroatom merupakan salah satu penyebab utama dihasilkannya polutan, menyebabkan stabilitas yang rendah saat penyimpanan dan transportasi. Heteroatom juga berperan sebagai inhibitor dan racun dalam proses pengilangan katalitik yang menggunakan molybdenum atau tungsten sulfida dengan promotor cobalt atau nikel pada alumina atau silika alumina.

Untuk memenuhi peraturan tentang polusi udara oleh emisi gas buang disel, pemrosesan minyak ringan (GO, gas oil) sebagai umpan untuk produksi bahan bakar disel akan membutuhkan temperatur dan tekanan reaksi yang lebih tinggi. Proses yang digunakan juga membutuhkan katalis yang lebih aktif agar memenuhi spesifikasi sulfur dalam produk (saat ini batasan sulfur $0.05 \%$ berat di banyak negara) (T.Takatsuka et al., 1992).

Telah diketahui bahwa desulfurisasi minyak ringan harus menghilangkan senyawa sulfur yang susah dihilangkan seperti turunan dibenzotiofen, khususnya pada konsentrasinya yang sangat rendah (D.D. Whitehurst et.a., 1998). Selain itu, kinerja katalis mengalami hambatan oleh $\mathrm{H}_{2} \mathrm{~S}$ yang dihasilkan dari senyawa sulfur reaktif dan senyawa aromatik, yang mempersulit aktivitas desulfurisasinya (S. Kasahara et.al., 1997 \& P. Zeuthen et.al., 2001). Senyawa nitrogen telah diketahui dapat menghambat hidrodesulfurisasi minyak ringan (M.J. Girgis et.al., 1991 \& SD Sumbogo Murti et.al., 2000). Tetapi hambatan dalam proses desulfurisasi, sejauh ini diabaikan untuk memenuhi peraturan yang berlaku.

Kajian ini bertujuan untuk mengetahui dan menjelaskan pengaruh katalitik terhadap HDS minyak ringan, menggunakan katalis konvensional NiMoS $/ \mathrm{Al}_{2} \mathrm{O}_{3}$. Suatu minyak ringan (GO) dan minyak ringan yang bebas senyawa nitrogen (NF-GO) dihidrodesulfurisasi dengan katalis komersial di dalam sebuah autoklaf untuk menjelaskan pengaruh senyawa nitrogen terhadap reaktifitas HDS dari setiap senyawa 
sulfur dalam minyak ringan. HDS selalu menghasilkan $\mathrm{H}_{2} \mathrm{~S}$, yang akan menghambat HDS secara kuat. Oleh karena itu proses bertahap dilakukan dalam penelitian ini di mana suasana reaksi diganti dengan hidrogen murni pada tahap awal untuk menghilangkan hambatan oleh $\mathrm{H}_{2} \mathrm{~S}$ yang dihasilkan, sebelum prosesnya dilanjutkan.

\section{EKSPERIMEN}

\subsection{Umpan}

Beberapa sifat GO dan NF-GO ditampilkan pada Tabel 1. Katalis $\mathrm{NiMo} / \mathrm{Al}_{2} \mathrm{O}_{3}$ yang tersedia secara komersial digunakan dalam kajian ini. Sebelum reaksi, katalis dipresulfidasi dengan aliran $5 \%$ vol $\mathrm{H}_{2} \mathrm{~S} / \mathrm{H}_{2}$ pada $360{ }^{\circ} \mathrm{C}$ selama 2 jam.

Tabel 1. Komposisi GO dan NF-GO

\begin{tabular}{|l|l|l|}
\hline & GO & NF-GO \\
\hline Karbon (\% berat) & 85.95 & 86.04 \\
\hline Hidrogen (\% berat) & 12.3 & 12.3 \\
\hline Sulfur (\% berat) & 1.64 & 1.6 \\
\hline Nitrogen (ppm) & 300 & 0 \\
\hline
\end{tabular}

\subsection{Hydrotreatment}

Hydrotreatment minyak ringan dilakukan dalam autoklaf $100 \mathrm{ml}$. Minyak ringan(GO) sebanyak 10 $\mathrm{g}$ di-hydrotreating pada temperatur $340{ }^{\circ} \mathrm{C}$ dan tekanan $5 \mathrm{MPa}$ (tekanan awal hidrogen pada temperatur ruang) dengan $1 \mathrm{~g}$ katalis melalui konfigurasi reaksi satu tahap dan dua tahap seperti yang ditunjukkan pada Gambar 1. Waktu reaksi untuk reaksi satu tahap adalah 30 dan 60 menit, sedangkan reaksi dua tahap terdiri dari 2 reaksi 30 menit. Tahap kedua dilakukan setelah memperbarui suasana reaksi dengan $\mathrm{H}_{2}$ baru pada temperatur ruang.

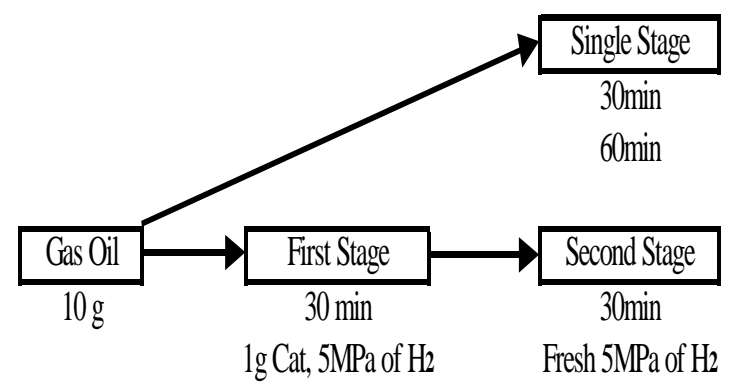

Gambar 1. Konfigurasi hydrotreatment

\subsection{Pengukuran}

Senyawa karbon, sulfur dan nitrogen dalam GO dimonitor menggunakan kromatografi gas dengan detektor emisi atom (GC-AED). GC Hewlett Packard (HP6890) yang dipasangkan dengan detektor emisi atom (G2350A) digunakan pada kajian ini. Prosedur dan kondisi detail untuk analisa GC dilaporkan dalam makalah lain.

\section{HASIL DAN PEMBAHASAN}

\subsection{Minyak Ringan (Umpan)}

Gambar 2 menunjukkan kromatogram karbon, sulfur dan nitrogen dari GO dan NF-GO umpan. Pada dasarnya GO terdiri dari hidrokarbon parafinik seperti yang ditunjukkan oleh puncak yang tajam (gb 2a). Senyawa sulfur yang ditemukan dalam GO adalah alkilbenzotiofen (BTs) yang memiliki rantai alkil C2-C5, dibenzotiofen (DBT), dan dibenzotiofen teralkilasi. Senyawa nitrogen dalam minyak yang pada dasarnya bukan berbasis nitrogen seperti karbazol (Cz), karbazol monometilasi (C1-Cz) dan karbazol dimetilasi (C2-Cz).

Hampir tidak ada puncak yang teramati karena senyawa nitrogen pada kromatografi, menunjukkan senyawa berbasis nitrogen di GO hanya sedikit. Kromatogram karbon dan sulfur dari NF-GO (Gambar 2b) pada dasarnya sama dengan GO. Tidak ada puncak nitrogen teramati di NF-GO, senyawa nitrogen telah dikeluarkan sepenuhnya dari GO.

\subsection{Reaktifitas GO dan NF-GO dengan Katalis NiMos}

Gambar 3 membandingkan reaktifitas $\mathrm{GO}$ dan NF-GO dengan katalis NiMoS. Reaksi selama 30 menit berhasil menghilangkan sebagian besar senyawa sulfur reaktif seperti tiofen dan kadar sulfur dalam minyak masing-masing adalah 2245 dan 1079 ppm. Angka tersebut menunjukkan perbedaan yang signifikan karena pengaruh penghilangan nitrogen.

Perpanjangan waktu reaksi sampai 60 menit meningkatkan HDS kedua minyak secara signifikan dan masing-masing kadar sulfur menjadi 901 dan 260. Hal ini terjadi juga karena pengaruh senyawa nitrogen. HDS dua tahap dengan pembaharuan suasana hidrogen yang dilakukan diantara tahap pertama dan kedua meningkatkan desulfurisasi. Kadar sulfur dari minyak masing-masing turun menjadi 349 dan 129 ppm.

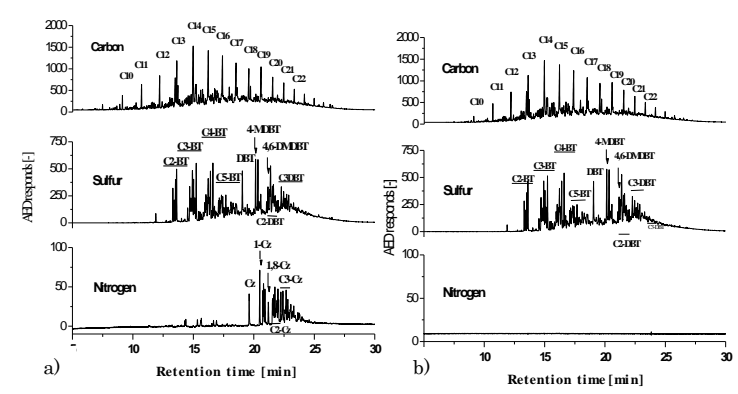

Gambar 2. Kromatogram GC AED dari minyak disel a) GO,b) NF-GO 

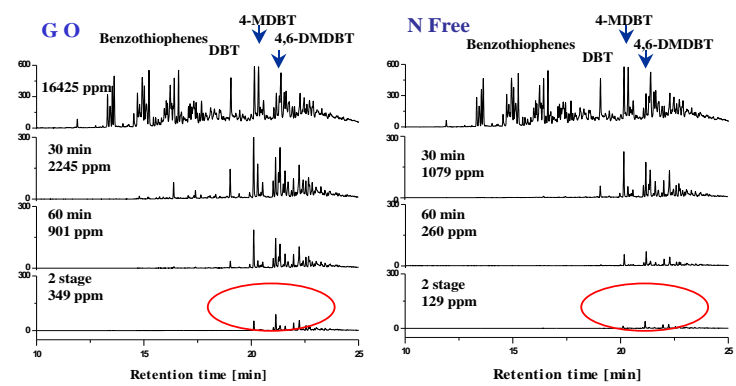

Gambar 3. Kromatogram GC AED dari HDS minyak diesel.

Penghilangan senyawa nitrogen sangat effektif meningkatkan desulfurisasi dengan katalis NiMoS pada setiap tahap reaksi. Pengaruhnya menjadi lebih signifikan dengan kemajuan HDS. Efek menguntungkan dari penghilangan $\mathrm{H}_{2} \mathrm{~S}$ untuk tahap kedua juga ditandai pada katalis ini.

\subsection{Reaktivitas Senyawa Sulfur yang Sulit Dihilangkan dalam GO dan NF-GO}

Sejumlah senyawa sulfur yang sulit dihilangkan seperti DBT dan DBTs teralkilasi yang terkandung dalam GO awal masih tersisa dalam produk HDS dengan waktu reaksi 60 menit untuk hydrotreatment satu tahap dan dua tahap. Tabel 2 menunjukkan reaktifitas DBT, 4-MDBT dan 4,6DMDBT secara kuantitatif dalam hydrotreatment satu tahap dan dua tahap dengan katalis NiMoS. DBT adalah senyawa yang paling reaktif diantara senyawa sulfur yang sulit dihilangkan. Reaksi dua tahap dengan mengubah suasana reaksi dengan $\mathrm{H}_{2}$ baru dapat meningkatkan HDS senyawa sulfur yang sulit dihilangkan. Penghilangan nitrogen juga efektif meningkatkan HDS pada setiap tahap reaksi, khususnya untuk 4-MDBT dan 4,6-DMDBT.

Harus diperhatikan bahwa penghilangan nitrogen lebih efektif daripada penggantian $\mathrm{H}_{2}$ untuk HDS 4-MDBT dan 4,6-DMDBT dengan NiMoS. Hal ini menunjukkan bahwa hambatan/inhibisi pada sebagian katalis ini disebabkan oleh senyawa nitrogen yang tertinggal.

Tabel 2. Reaktivitas senyawa sulfur yang sulit dihilangkan

\begin{tabular}{|c|c|c|c|c|c|}
\hline & & $\begin{array}{c}\text { Umpan } \\
(\mathrm{ppm})\end{array}$ & $\begin{array}{c}30 \\
\text { menit } \\
(\mathrm{ppm})\end{array}$ & $\begin{array}{l}60 \text { menit } \\
(\mathrm{ppm})\end{array}$ & $\begin{array}{c}2 \text { tahap } \\
(\mathrm{ppm})\end{array}$ \\
\hline \multirow[b]{2}{*}{ DBT } & $\mathrm{GO}$ & 205 & 54 & 12 & 0 \\
\hline & $\begin{array}{l}\text { NF- } \\
\text { GO }\end{array}$ & 205 & 20 & 2 & 0 \\
\hline \multirow[b]{2}{*}{ 4-MDBT } & $\mathrm{GO}$ & 234 & 134 & 70 & 23 \\
\hline & $\begin{array}{l}\text { NF- } \\
\text { GO }\end{array}$ & 234 & 83 & 19 & 5 \\
\hline \multirow{2}{*}{$\begin{array}{c}4,6- \\
\text { DMDBT }\end{array}$} & $\mathrm{GO}$ & 114 & 74 & 54 & 37 \\
\hline & $\begin{array}{l}\text { NF- } \\
\text { GO }\end{array}$ & 114 & 62 & 24 & 17 \\
\hline
\end{tabular}

\subsection{Reaktivitas Senyawa Nitrogen}

Hidrodenitrogenasi (HDN) berjalan bersamaan dengan HDS. Gambar 4 menunjukkan pencapaian HDN pada setiap tahap reaksi. Senyawa nitrogen dengan titik didih lebih rendah dihilangkan lebih awal dan senyawa yang berat lebih banyak tertinggal dalam reaksi. Kandungan total senyawa nitrogen turun ke $30 \%$ (107 ppm) dari kandungan awal nitrogen melalui reaksi selama 30 menit. Penurunan bisa sampai ke 16 $\%$ (48 ppm) dengan penambahan reaksi satu tahap selama 30 menit. Hydrotreatment dua tahap dengan penggantian suasana hidrogen di antara kedua tahapan meningkatkan HDN, kadar nitrogen mencapai $8 \%$ atau $24 \mathrm{ppm}$.

Reaktivitas HDN dari senyawa nitrogen ditunjukkan pada Tabel 3. Karbazol adalah senyawa yang paling reaktif dan benar benar bisa dihilangkan melalui HDN selama 60 menit. Karbazol teralkilasi menunjukkan reaktifitas yang kurang. HDN dua tahap meningkatkan penurunan kadar nitrogen untuk semua senyawa.

Tabel 3. HDN senyawa nitrogen

\begin{tabular}{|c|c|c|c|c|}
\hline & $\begin{array}{l}\text { Umpan } \\
\text { (ppm) }\end{array}$ & $\begin{array}{c}30 \\
\text { menit } \\
(p p m)\end{array}$ & $\begin{array}{c}60 \\
\text { menit } \\
(p p m)\end{array}$ & $\begin{array}{c}2 \\
\text { tahap } \\
\text { (ppm) }\end{array}$ \\
\hline Karbazol (Cz) & 9 & 2 & 0 & 0 \\
\hline 1- $\quad \mathrm{Cz}$ & 15 & 4 & 1 & 1 \\
\hline $\mathrm{Cz}$ & 10 & 2 & 1 & 1 \\
\hline $\mathrm{Cz}$ & 7 & 2 & 1 & 0 \\
\hline 4- $\quad \mathrm{Cz}$ & 10 & 4 & 1 & 1 \\
\hline 1,8 - Cz & 16 & 4 & 2 & 1 \\
\hline $2,4-C z$ & 9 & 3 & 1 & 0 \\
\hline $2,5-C z$ & 6 & 3 & 1 & 0 \\
\hline $2,3-C z$ & 9 & 4 & 2 & 1 \\
\hline $3,4-\mathrm{Cz}$ & 3 & 1 & 1 & 0 \\
\hline $1,4,8-\mathrm{Cz}$ & 11 & 6 & 3 & 3 \\
\hline $1,3,5-\mathrm{Cz}$ & 13 & 6 & 2 & 1 \\
\hline $1,5,7-\mathrm{Cz}$ & 10 & 6 & 3 & 2 \\
\hline
\end{tabular}

\subsection{Pembahasan}

Kajian ini dilakukan untuk menjelaskan pengaruh hambatan senyawa nitrogen dalam GO pada desulfurisasi senyawa sulfur pada $G O$ yang sama dengan membandingkan HDS GO dan NFGO. Pengaruh hambatan senyawa nitrogen yang muncul secara unik, menunjukkan kontribusi inhibitor lain, sifat asal katalis dan rasio inhibitor/substrat, yang bervariasi dengan kemajuan reaksi. Pembatasan kondisi oleh reaktor batch autoklaf menentukan peranan inhibitor dengan menjaga semua produk dan substrat yang tidak bereaksi, kecuali jika suasana diperbarui seperti yang dilakukan dalam reaksi bertahap pada kajian ini.

Penghilangan nitrogen efektif pada HDS GO dalam tahap reaksi pertama dan kedua. Desulfurisasi senyawa sulfur reaktif memperbanyak $\mathrm{H}_{2} \mathrm{~S}$ dalam autoklaf, yang menghambat desulfurisasi dari senyawa sulfur 
yang kurang reaktif. Hambatan kuat dari produk ini harus diperhitungkan sebelum inhibisi senyawa nitrogen dibahas. Pengaruh hambatan senyawa nitrogen bersaing dengan pengaruh inhibisi $\mathrm{H}_{2} \mathrm{~S}$ pada senyawa tak terdesulfurisasi. Penghilangan nitrogen lebih efektif daripada pembaharuan suasana pada tahap kedua dengan reaksi selama 60 menit.

Kombinasi penghilangan nitrogen dan penggantian $\mathrm{H}_{2}$ pada tahap kedua sangat efektif untuk mencapai HDS yang tinggi.

Inhibisi senyawa nitrogen pada katalis sulfida bisa menggambarkan sifat asam katalis. Keasaman telah diakui dapat meningkatkan HDS melalui peningkatan desorpsi $\mathrm{H}_{2} \mathrm{~S}$, hidrogenasi dan isomerisasi senyawa sulfur. Oleh karena itu, harus diperhatikan bahwa keasaman katalis bisa meningkatkan inhibisi dari senyawa nitrogen. Keasaman yang paling sesuai harus dirancang pada katalis dengan pemilihan bentuk sulfida, support dan aditif.

HDS senyawa sulfur yang sulit dihilangkan berjalan cepat dengan katalis $\mathrm{NiMo} / \mathrm{Al}_{2} \mathrm{O}_{3}$ tanpa hambatan dari senyawa $\mathrm{H}_{2} \mathrm{~S}$ dan nitrogen seperti yang teramati dengan model reaksi, meskipun kondisi preparasi juga sangat berpengaruh. Katalis $\mathrm{NiMo} / \mathrm{Al}_{2} \mathrm{O}_{3}$ juga menghilangkan senyawa nitrogen bersamaan dengan HDS. Konsentrasi $\mathrm{H}_{2} \mathrm{~S}$ yang tinggi tidak mematikan aktivitas hidrogenasi $\mathrm{NiMo} / \mathrm{Al}_{2} \mathrm{O}_{3}$. Oleh karena itu, pertama-tama senyawa nitrogen dasar dihilangkan dan karbazol dengan atau tanpa substitusi alkil secara perlahan dihilangkan pada kondisi tersebut.

Tingkat reaktivitas karbazol juga dipertegas dalam kajian ini, meskipun sejumlah senyawa nitrogen tidak sepenuhnya teridentifikasi dalam kajian ini. Ada senyawa nitrogen yang sangat sulit dihilangkan ditemukan pada tingkat titik didih tertinggi. Karbazol dengan lebih banyak substituen metil menunjukkan reaktifitas yang lebih rendah. Sekitar 100 - 180 ppm senyawa nitrogen (terutama karbazol) tertinggal dalam GO setelah tahap pertama berjalan 30 menit. Kadar senyawa nitrogen ini ditemukan lebih menghambat desulfurisasi dari 700 sampai 3000 ppm senyawa sulfur yang sulit dihilangkan pada tahap kedua.

Senyawa sulfur yang sulit dihilangkan pada konsentrasi sedikit dapat mengalami inhibisi lebih banyak oleh sedikit konsentrasi senyawa nitrogen. Kemapuan adsorpsi senyawa sulfur yang kurang menyebabkan terjadinya lebih banyak hambatan/inhibisi dari inhibitor, yang bersaing dengan situs aktif katalis sulfida.

HDS dari senyawa sulfur yang sulit dihilangkan berjalan lebih cepat tanpa inhibisi dari $\mathrm{H}_{2} \mathrm{~S}$ dan senyawa nitrogen. Katalis juga menghilangkan senyawa nitrogen bersamaan dengan HDS. Konsentrasi $\mathrm{H}_{2} \mathrm{~S}$ yang tinggi tidak mematikan aktivitas hidrogenasi NiMo. Pada beberapa kondisi, senyawa nitrogen dasar dihilangkan pertama kali dan karbazol dengan atau tanpa tersubstitusi alkil tereliminasi secara lambat.

\section{KESIMPULAN}

Senyawa nitrogen dapat berperan sebagai inhibitor pada hidrodesulfurisasi minyak disel. Kombinasi penghilangan nitrogen dan penggantian $\mathrm{H}_{2}$ sangat efektif untuk memperoleh hidrodesulfurisasi minyak ringan yang tinggi dengan katalis NiMoS/ $/ \mathrm{Al}_{2} \mathrm{O}_{3}$.

Senyawa sulfur yang sulit dihilangkan dapat dibuang secara efektif dengan penghilangan senyawa nitrogen dan pembaharuan hidrogen dalam HDS bertahap, menunjukkan pengaruh sinergi karena terjadinya penghilangan dua inhibitor secara bersamaan.

\section{DAFTAR PUSTAKA}

Girgis, M. J.; Gates, B. C.; 1991. Reactivites, Reaction Network And Kinetics In HighPressure Catalytic Hydro processing. Ind. Eng. Chem. Res., 30, 2021-2058

Kasahara, S.; Shimizu, T.; Yamada, M.; 1997. Inhibiting Effects Of H2S On HDS Activity Of Como-, Nimo- And $\mathrm{Mo} / \mathrm{Al}_{2} \mathrm{O}_{3}$. Catalyst Today, $35,59-64$

Sumbogo Murti,SD, K. Sakanishi, I. Mochida, 2000 "Molecular Composition Of Coal Liquid Oil Characterized By Gas Chromatography With Atomic Emission Detector" Division Of Fuel Chemistry, American Chemical Society, Washington DC, 45, 4, 860-864

Takatsuka, T.; Wada, Y.; Suzuki, H.; Komatsu, S.; Morimura, Y. .1992. Deep Desulfurization Of Diesel Fuel And Its Color Degradation. Journal .Petroleum Institute Japan, 35, 179187

Whitehurst, D. D.; Isoda, T.; Mochida, I. 1998. Present State Of The Art And Future Challenges In The Hydrodesulfurization Of Polyaromatic Sulfur Compounds. Advances In Catalysis., 42, 345-471

Zeuthen, P.; Knudsen, G. K.; Whitehurst, D.D., 2001. Organic Nitrogen Compounds In Gas Oil Blends, Their Hydrotreated Products And Importance To Hydrotreatment. Catalyst Today, $65,307-314$ 